Revista do Departamento de Geografia
Universidade de São Paulo
www.revistas.usp.br/rdg
ISSN 2236-2878

\title{
EVENTOS DE PRECIPITAÇÃO EXTREMA E IMPACTO METEÓRICO NA BACIA HIDROGRÁFICA DO IGARAPÉ CEREJA, ÁREA URBANA DE BRAGANÇA-PA, DURANTE O INVERNO AMAZÔNICO DE 2014
}

\section{EXTREME RAINFALL EVENTS AND METEORIC IMPACT IN HYDROGRAPHIC BASIN OF IGARAPÉ CEREJA, URBAN AREA OF BRAGANCA-PA, DURING THE WINTER OF AMAZON IN 2014}

\author{
Tarcísio Oliveira da Costa \\ Secretaria de Estado de Educação do Pará, SEDUC \\ cisocosta@hotmail.com \\ Cássio Arthur Wollmann \\ Universidade Federal de Santa Maria \\ cassio_geo@yahoo.com.br
}

Recebido (Received): 25/05/2016 DOI:10.11606/rdg.v0i0.115686

\begin{abstract}
This study concerns in to analyze extreme precipitation events and meteoric impact in the hydrographic basin of Igarapé Cereja, urban area of Bragança-PA, during the Amazonian winter of 2014. Therefore, the research was based on the SCU theory developed by Monteiro (1976). Meteorological data analyzed were collected Weather Station Conventional of Tracuateua (EMT) and Weather Station Automatic of Bragança (EMB) belonging to INMET, and it was installed a network of 07 rain gauges installed in the urban area of Bragança/PA that enabled development of variability maps precipitation during the rainy season 2014 in the area of Igarapé Cereja. With the aid of satellite images GOES 13 provided by INPE and Synoptic maps of the Navy of Brazil the active atmospheric systems were raised. With the results, it was observed that the ITCZ has increased participation in the occurrence of extreme events and urban impacts. There is a great variability of rainfall in the study area, up to $161 \mathrm{~mm}$ between the north-northeast sector (wettest) and the south-southwest sector (less rain).
\end{abstract}

Keywords: Extreme precipitation, Watersheds, Urban areas, Bragança-PA.
Palavras-chave: Precipitação extrema, Bacias hidrográficas, Áreas urbanas, Bragança-PA. 


\section{INTRODUÇÃO}

Os problemas causados ao meio ambiente constituem um dos maiores desafios contemporâneos para a sociedade, onde a chamada "questão ambiental" não tem uma relação sempre harmoniosa com as necessidades de desenvolvimento e os interesses econômicos, pois na sociedade que se vive, a ideia de desenvolvimento aparece quase sempre como incompatível com a proteção e a conservação da natureza.

Neste sentido, Sachs (1986, p.65) coloca que: “As necessidades do homem são determinadas pela economia e pelo mercado, quando na verdade, esta equação deveria ser invertida. É a sociedade quem deveria, através de suas necessidades, determinar os padrões de produção, consumo e desenvolvimento".

Ao aliarmos essa problemática com a forma como vem sendo conduzido o crescimento e expansão urbana no Brasil, também são desconsiderados em grande parte as características naturais do meio, que aliado à falta de infraestrutura, vem ocasionando inúmeras alterações negativas para a qualidade do meio ambiente urbano e sua população. Na Amazônia essas características são mais evidentes ainda, uma vez que é peculiar da região a existência de cidades ribeirinhas, cujos rios e igarapés são o principal meio para transporte, abastecimento e manutenção da dinâmica local e regional (COSTA, 2012).

O município de Bragança, área de estudo desta pesquisa, situa-se na região nordeste do estado do Pará, tem sua sede localizada à margem esquerda do Rio Caeté, que é um importante rio desta porção do referido Estado, e possui população estimada pelo IBGE (2014) em 120.124 habitantes, ocupando uma área de $23.337 \mathrm{~km}^{2}$, dos quais $16,1 \mathrm{~km}^{2}$ são área urbana, sendo uma das maiores cidades do Pará.

O Igarapé Cereja é um afluente do Rio Caeté, e corta a área urbana do município, passando por 06, dos 18 bairros da cidade. A paulatina ocupação nas margens do Igarapé Cereja, em especial ao longo dos últimos anos, tem acarretado uma série de problemas de ordem social e ambiental, sendo mais expressivas as constantes enchentes que afetam a população local (op. cit. 2012).

A forma com que a expansão da cidade vem ocorrendo, seguindo uma tendência nacional, ao longo do tempo, vem acarretando uma série de ocupações ao longo das margens deste rio que já serviu de fonte de abastecimento de água e ao lazer da população (Op. cit, 2012). Para Tucci (2002), esse crescimento urbano, de uma maneira geral, vem sendo caracterizado pela expansão irregular da periferia, não obedecendo ao Plano Diretor ou normas específicas de loteamentos, além da ocupação irregular de áreas públicas e de proteção, sobretudo pela população de baixa renda, o que dificulta as ações não estruturais de controle ambiental urbano. Nota-se, no entanto, que a tendência predominante nas cidades brasileiras no tocante à solução de problemas dessa ordem, dá-se através da implantação de obras corretivas de engenharia, ao contrário de alternativas para prevenção a partir do planejamento urbano, por exemplo.

Para o ambiente urbano, o clima também é considerado uma das características naturais marcantes (WOLLMANN; SIMIONI, 2013) e por tal razão, merece especial atenção quando do planejamento da ocupação dessa área. Mesmo com essa importância, o clima não é tratado com a devida atenção pelos planejadores e governantes.

É comum aos pesquisadores, mesmo na área de Geografia, considerar o meio urbano isento de atenção quanto aos aspectos físicos. No tocante à Climatologia, esse quadro é mais agravante, e inadmissível conforme Garcia; Vide (2000), pois os habitantes das cidades respiram e estão sujeitos a ventos e chuvas, mesmo que estes sejam alterados em relação às áreas em seu entorno, da mesma forma que são afetados reciprocamente pelas mudanças de temperatura, umidade, entre outros elementos climáticos.

Deste modo, desconsiderar o fator clima no planejamento urbano torna este último inconsistente e, por fim, ineficiente no trato de problemas que derivam da variável climática, como as enchentes, uma vez que o ambiente não é composto somente das formações topográficas, da rede de drenagem, e da vegetação, mas das influências determinantes das condições climáticas locais e regionais (op. cit. 2000).

Na Amazônia, a negligência quanto à variável climática torna-se um agravante de maior proporção, dada as condições do clima regional, sobretudo no referente à precipitação pluviométrica e a ocorrência de eventos extremos associados e este canal de análise climática, pois frequentemente afetam as cidades com alagamentos, cheias e enchentes de magnitude e repercussão expressivas. É nesse sentido, que esta pesquisa, ao considerar o clima local e regional do Nordeste do Pará, pretende dar maior visão das enchentes que ocorrem nos espaços urbanos, como o caso das ocorridas no Igarapé Cereja, na cidade de Bragança. Nesse contexto, esta pesquisa teve como objetivo geral analisar a espacialidade e intensidade dos eventos de precipitação extrema e à ocorrência de enchentes na bacia hidrográfica do Igarapé Cereja, na área urbana de Bragança-PA, durante o inverno amazônico de 2014. 


\section{CARACTERIZAÇÃo GEOGRÁFICA DA ÁREA DE ESTUDO}

Situada na Mesorregião Nordeste Paraense, Microrregião Bragantina (Zona Bragantina), no limite entre a planície litorânea amazônica e o planalto rebaixado da Amazônia, entre as Coordenadas Geográficas $01^{\circ} 01^{\prime} 51^{\prime}$ 'S / 46 $45^{\prime} 22^{\prime}$ 'W e $01^{\circ} 04^{\prime} 34^{\prime}$ 'S e $46^{\circ} 47^{\prime} 04^{\prime \prime} \mathrm{W}$ (Figura 1), o município de Bragança tendo sua sede localizada à margem esquerda do Rio Caeté, e segundo o IBGE (2013), o município possui uma área de $23.337 \mathrm{~km}^{2}$, dos quais $16,1 \mathrm{~km}^{2}$ pertencem à área urbana do município $(0,06 \%$ do território), com população estimada de 120.124 habitantes em 2014, e densidade demográfica de 54,13 hab./km².

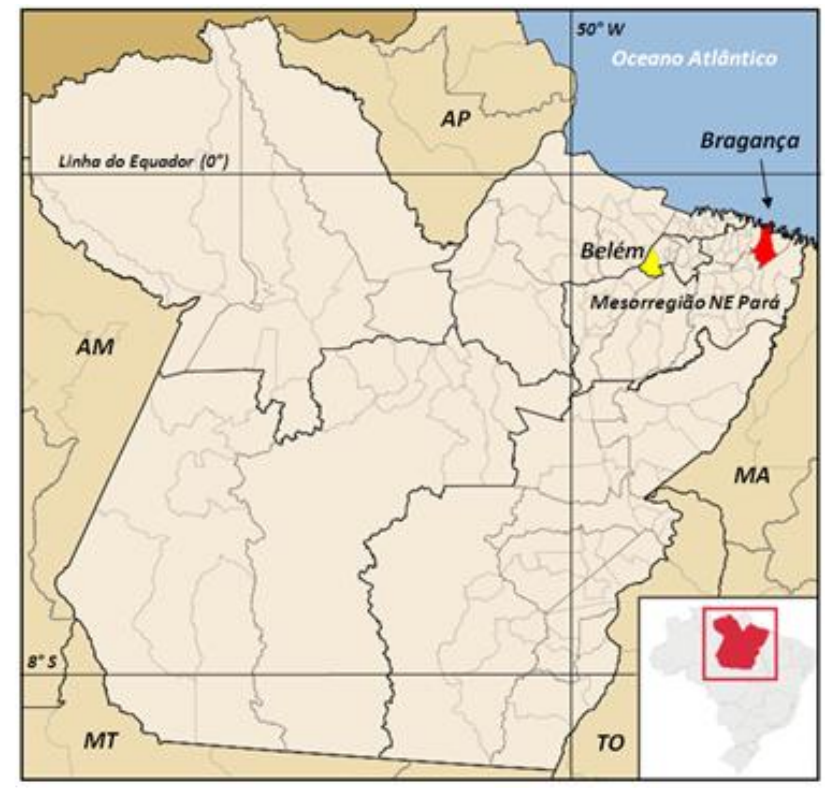

Figura 1: Mapa de Localização do município de Bragança - PA. Fonte: IBGE (2014)/Adapt.: Os autores (2014).

A área de estudo propriamente dita corresponde à micro bacia hidrográfica do Igarapé Cereja, sendo sua maior parte situada na área urbana do município de Bragança/PA, com altitudes entre $0 \mathrm{~m}$ e $60 \mathrm{~m}$. O Igarapé $^{1}$ Cereja é afluente do Rio Caeté, importante rio do nordeste do Pará, que se insere na Região Hidrográfica Costa Atlântica Nordeste e na Bacia Hidrográfica Costa Atlântica.

A área de estudo dessa pesquisa compreende a bacia hidrográfica do Igarapé Cereja, uma sub-bacia do Rio Caeté, localizada no nordeste do estado do Pará, na área urbana do município de Bragança, a $210 \mathrm{~km}$ da capital do estado, Belém. A bacia hidrográfica em estudo compreende uma pequena área que envolve quase a totalidade da área urbana de Bragança, tendo 11 dos 12 bairros oficiais localizados pelo menos uma pequena parte no perímetro da bacia hidrográfica, com exceção do bairro Riozinho, que se localiza em sua totalidade fora da área da bacia hidrográfica em estudo conforme mostrou o mapa da Figura 2.

\section{MATERIAIS E MÉTODOS}

As etapas definidas para a execução deste trabalho tiveram como embasamento teórico o Sistema Clima Urbano (SCU) proposto por Monteiro (1976), dando ênfase ao terceiro canal de percepção do Clima Urbano, denominado de Impacto Meteórico.

O desenvolvimento deste trabalho partiu das etapas previamente definidas, das quais a primeira etapa consistiu da definição da temática a ser investigada com consequente elaboração dos objetivos e a justificativa para a escolha do tema e área de estudo. Em seguida, elaborou-se pesquisa bibliográfica para construção da fundamentação teórica que aborda inicialmente a urbanização e suas implicações sobre o meio ambiente.

\footnotetext{
${ }^{1}$ Igarapé é um termo oriundo da língua indígena Tupi que significa “caminho de canoa". Muito utilizado na região amazônica para definir o curso de um rio ou canal estreito ou pequeno, conhecidos por darem passagem apenas a pequenas embarcações devido a pouca profundidade. Os igarapés costumam ficar escondidos no interior de matas e mesmo com o tamanho não deixam de ser uma importante via de transporte
} 


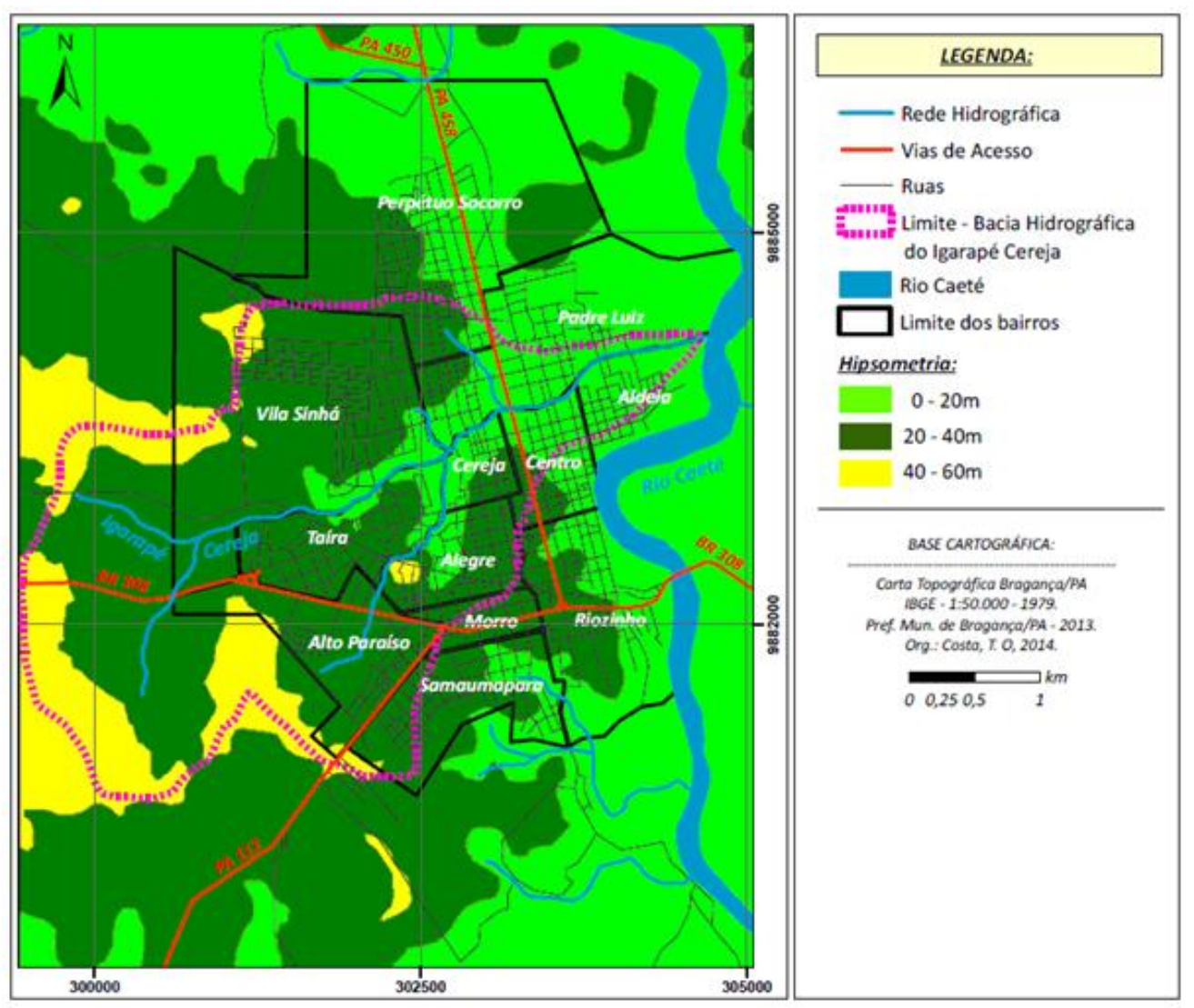

Figura 2: Mapa de Situação e Localização da cidade de Bragança, PA - e da Bacia Hidrográfica do Igarapé Cereja

Posteriormente fez-se uma revisão em torno da Teoria Geral dos Sistemas, passando em seguida à discussão em torno da proposta do Sistema Clima Urbano (SCU) de Monteiro (1976), que utilizou-se da abordagem sistêmica na formulação de sua teoria. No SCU, deu-se ênfase ao terceiro canal de percepção do clima urbano, o canal do impacto meteórico. Em seguida, analisou-se a dinâmica atmosférica regional da Amazônia, e as características do clima na área de estudo, e, posteriormente revisou-se o conceito de enchente, finalizando com a análise e discussão dos resultados.

Para a coleta de dados meteorológicos, foi utilizada a Estação Meteorológica Convencional de Tracuateua/PA, localizada a $15 \mathrm{~km}$ de Bragança/PA, nas coordenadas $1^{\circ} 07^{\prime} 00^{\prime \prime} \mathrm{S}$ e $46^{\circ} 09^{\prime} 00^{\prime}$ ' W e pertencente ao Instituto Nacional de Meteorologia (INMET). A escolha desta estação se deve ao fato da Estação Automática de Bragança/PA, também pertencente ao INMET, ter iniciado sua operação em março de 2008, portanto, não abrangendo de forma integral o recorte histórico da pesquisa, bem como por esta estação ainda não possuir uma Normal Climatológica, necessária para os estudos climáticos, devido ao pouco tempo em operação.

Considerando segundo Azevedo (2001, p. 155) que “... a investigação dos impactos de precipitação sobre as áreas urbanas implica numa abordagem de sua distribuição com detalhamento espacial e temporal especifico", considerou-se necessário uma análise da distribuição da precipitação pluvial extrema no tempo e espaço da área da bacia hidrográfica do Igarapé Cereja ao longo do período chuvoso na região (inverno amazônico) no ano de 2014, que é um dos anos de execução desta pesquisa. Deste modo, foi instalada uma rede de pluviômetros para a coleta de dados pluviométricos a ser analisado. A rede de pluviômetros justificase devido à escala de trabalho, que considera a bacia hidrográfica na área urbana como objeto da análise, pois as redes de instrumentos de medição meteorológicas oficiais existentes não são compatíveis com esta escala por ter escala de generalização muito grande e por isso mais compatível com a escala regional.

Neste contexto, para montagem da rede de pluviômetros selecionaram-se 07 pontos distintos em diferentes bairros de Bragança, dentro e fora dos limites da Bacia Hidrográfica do Igarapé Cereja. Os pluviômetros selecionados para serem utilizados nesta pesquisa são produzidos industrialmente em acrílico com régua milimétrica embutida e calibrada conforme o volume do reservatório do equipamento (Figura 3), com capacidade de armazenamento e medição de dados totais de 150 milímetros (mm). 


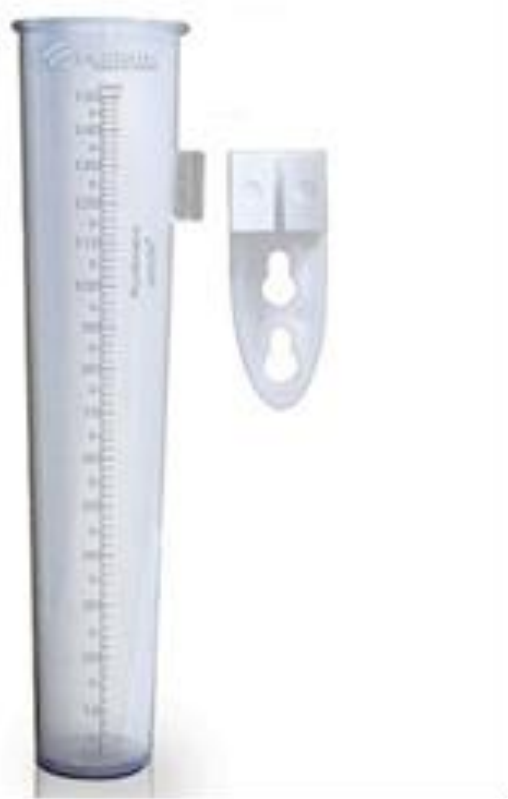

Figura 3: Pluviômetro analógico em acrílico com capacidade de 150 mm. (Marca: Incoterm).

Os 07 pluviômetros foram instalados na área que abrange a bacia hidrográfica do Igarapé Cereja e seu entorno imediato, a fim de dar maior precisão sobre a distribuição da precipitação especificamente sobre a área de estudo, conforme mostra o mapa da Figura 4.

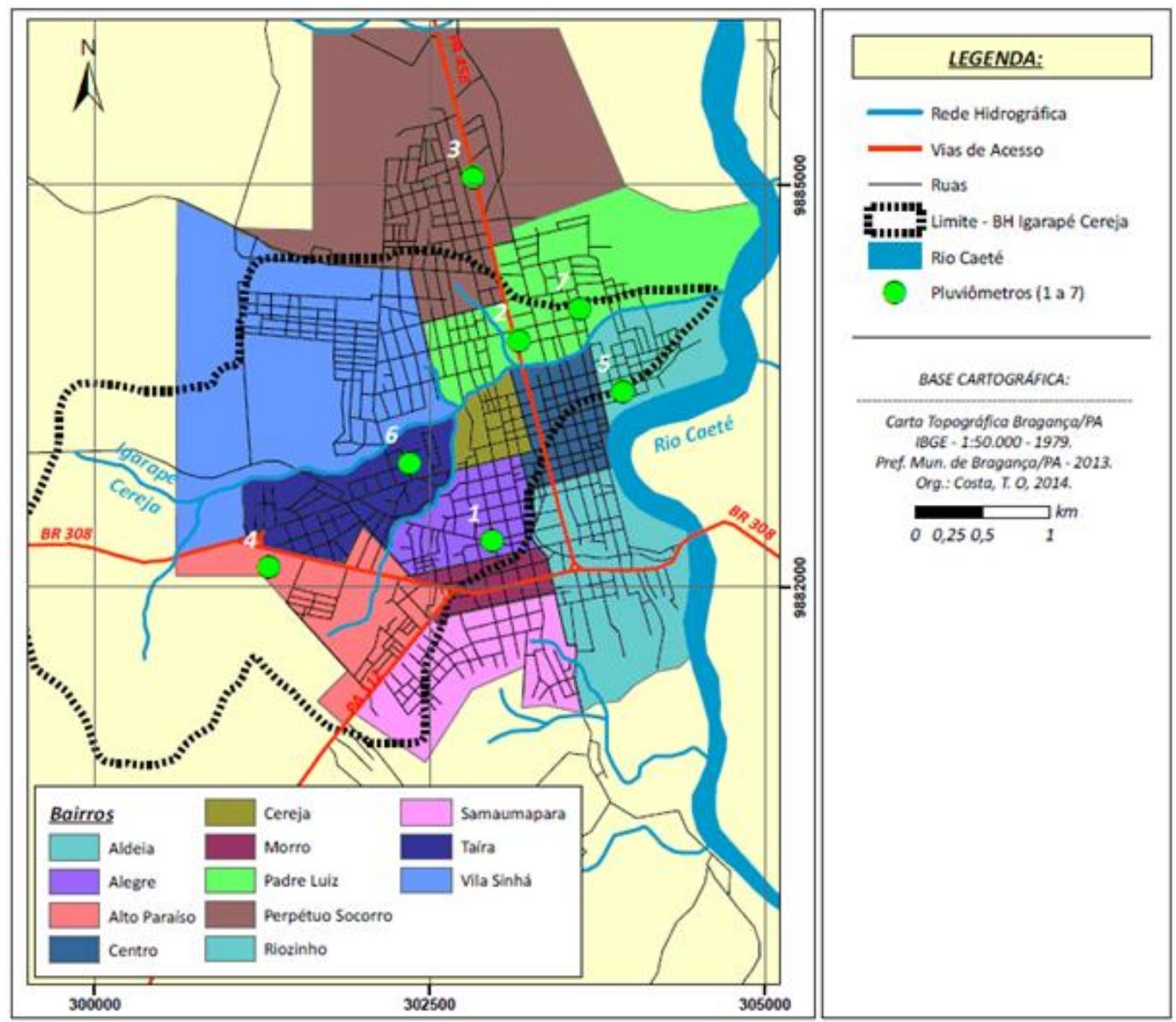

Figura 4: Localização dos bairros de Bragança/PA, e os pontos de coleta (pluviômetros) na Bacia Hidrográfica do Igarapé Cereja 
As coletas foram feitas diariamente às $21 \mathrm{~h}$, considerando-se para efeito da análise a chuva calculada em milímetros acumulada em $24 \mathrm{~h}$, ou seja, das $21 \mathrm{~h}$ do dia anterior, às $21 \mathrm{~h}$ do dia atual, pois conforme visto na revisão teórica, os sistemas convectivos dissipam-se à noite e voltam a atuar durante o final da madrugada e início do dia. Ainda, é neste mesmo horário que finda a leitura oficial da estação meteorológica de Tracuateua, às $21 \mathrm{~h}$, assim, optou-se pelo mesmo horário para posterior necessidade de comparação.

Para a instalação do equipamento de coleta de dados considerou-se a altura do pluviômetro a 1,5 m do solo, e livre de obstáculos, pois segundo Ayoade (2003), o volume de chuva captado em determinado local vai depender de vários fatores, tais como a altura do pluviômetro em relação ao solo, a velocidade do vento e a taxa de evaporação. Neste sentido, o pluviômetro deve estar bem protegido de obstáculos como árvores e paredes que poderão influenciar no volume de captação de dados, conforme as normas da Organização Mundial Meteorológica (WMO, 1994).

Os pluviômetros foram instalados em bases de madeira com 1,60 m de comprimento, sendo que a abertura do equipamento para coleta a uma distância de 1,50 $\mathrm{m}$ de altura do solo e o excedente da base serviu para fixação. Os pluviômetros foram encaixados num suporte fixo na base de madeira e um encaixe direto no reservatório, o que possibilita o apoio do material e fácil manuseio quando da coleta e reposição do instrumento.

Foi selecionado para coleta o período mais chuvoso na região, considerando assim os meses representativos da sazonalidade regional amazônica e de ocorrência de eventos extremos, que ocorrem de janeiro a maio, conforme visto na revisão teórica. Por fim a coleta dos dados foi feita diariamente durante os meses de janeiro a maio de 2014.

Para análise da distribuição pluviométrica na área urbana com ocorrência de eventos extremos no ano de 2014, foi utilizado para fins de análise o comparativo entre os dados da coleta em campo e da Estação Convencional Tracuateua/PA, pois mesmo havendo a Estação Automática Bragança/PA, com melhor cobertura da área em estudo, foi informado pelos técnicos do INMET que o equipamento de leitura pluviométrica desta estação apresentava problemas em seu funcionamento e aguardava manutenção sem data prevista para ocorrer. Deste modo, a Estação Convencional Tracuateua/PA por ser a mais próxima da área estudada e possuir uma Normal Climatológica para comparação se mostrou eficaz para o estudo, ainda que esta estação tenha passado por um período inoperante ( $1^{\circ}$ novembro de 2013 a 16 de janeiro de 2014).

Com os dados coletados nos postos pluviométricos, foi possível a construção de cartogramas de distribuição pluviométrica na bacia hidrográfica do Igarapé Cereja. Com auxílio do software Surfer 8.0 e do ArcGIS 9.3, foi possível a elaboração dos mapas de distribuição total mensal da precipitação (janeiro a maio) e da distribuição espacial da chuva em episódios extremos que levaram à ocorrência de repercussões negativas na área urbana de Bragança inserida na referida bacia hidrográfica.

A partir desses passos puderam-se identificar 11 eventos extremos, e suas repercussões no espaço urbano. Foi feita a espacialização da distribuição pluviométrica na área da bacia do Igarapé Cereja e identificaram-se os diferentes sistemas atmosféricos atuantes durante cada evento.

Para a identificação dos sistemas atmosféricos nos episódios analisados foram utilizadas as cartas sinóticas da Diretoria de Hidrografia e Navegação da Marinha do Brasil, com apoio das imagens do satélite GOES-13 no canal colorido e visível, disponíveis no Centro de Previsão do Tempo e Estudos Climáticos CPTEC, do Instituto Nacional de Pesquisas Espaciais - INPE.

\section{ANÁLISE E DISCUSSÃO DOS RESULTADOS}

A coleta de dados meteorológicos em campo, juntamente com as informações disponíveis na rede de Estações Meteorológicas do INMET e identificação de danos na área urbana causada pelas chuvas em 2014, possibilitou a identificação de 11 eventos extremos com relevante repercussão sobre a cidade como mostra o Quadro 1. Neste quadro, pode-se observar que dentre os eventos extremos identificados há um maior número de ocorrência devido atuação do sistema atmosférico CIT (63,63\% dos casos identificados), enquanto 36,37\% dos casos estão ligados a CIT associada com o sistema atmosférico IT.

Dentre os eventos citados, o ocorrido no dia 16 de fevereiro de 2014, apresentou o menor volume de precipitação observado $(56,4 \mathrm{~mm})$, podendo este valor ser considerado um índice para os eventos extremos com ocorrência de danos e enchentes. Considerando a distribuição mensal da ocorrência dos eventos, observou-se 01 caso em janeiro, $02 \mathrm{em}$ fevereiro, $02 \mathrm{em}$ março e $02 \mathrm{em}$ abril, enquanto maio apresentou 04 
eventos. Assim têm-se um percentual de ocorrência de 9,09\% no mês de janeiro, $18,18 \%$ nos meses de fevereiro, março e abril, enquanto maio apresentou o maior percentual $(36,36 \%)$ dos casos.

Quadro 1 - Eventos de precipitação extrema e participação de sistemas atmosféricos no ano de 2014.

\begin{tabular}{|c|c|c|c|c|}
\hline Episódio & Data do Evento & $\begin{array}{l}\text { Data de pico do } \\
\text { Evento }\end{array}$ & Precipitação Total (mm) & $\begin{array}{c}\text { Sistema } \\
\text { Atmosférico }\end{array}$ \\
\hline 01 & 08-09 jan. & 09 jan. & $132 \mathrm{~mm}$ & CIT \\
\hline 02 & 05-06 fev. & 06 fev. & $92,3 \mathrm{~mm}$ & CIT \\
\hline 03 & 16 fev. & 16 fev. & $56,4 \mathrm{~mm}$ & CIT/IT \\
\hline 04 & 02 mar. & 02 mar. & $71,6 \mathrm{~mm}$ & CIT \\
\hline 05 & 14-16 mar. & 16 mar. & $123,7 \mathrm{~mm}$ & CIT \\
\hline 06 & 08-11 abr. & 10 abr. & $220,7 \mathrm{~mm}$ & CIT \\
\hline 07 & $27-28$ abr. & 27 abr. & $82 \mathrm{~mm}$ & CIT \\
\hline 08 & 01-02 mai. & 01 mai. & $78,8 \mathrm{~mm}$ & CIT \\
\hline 09 & 06-08 mai. & 06 mai. & $98,2 \mathrm{~mm}$ & CIT/IT \\
\hline 10 & 10-12 mai. & 12 mai. & $105,6 \mathrm{~mm}$ & CIT/IT \\
\hline 11 & 20-22 mai. & 21 mai. & $90,3 \mathrm{~mm}$ & CIT/IT \\
\hline
\end{tabular}

Org.: Os autores.

Apesar de maio não ter sido o mês mais chuvoso, sendo este o mês de abril, foi o mês em que mais ocorreram eventos extremos de precipitação. Isso justifica-se devido a reorganização dos sistemas atmosféricos na região que passa a ter maior presença das IT e ainda com forte participação da CIT, mesmo este sistema estando em fase de desintensificação. Devido a essas condições é possível observar a maior concentração de eventos em associação desses dois sistemas no mês de maio além de maior percentual comparado a outros meses do inverno amazônico. Assim, a partir da coleta dos dados e identificação das características e repercussão de cada evento ocorrido em 2014, foram feitas análises individualizadas dos casos identificados e tratados como episódios nos itens seguintes desse capítulo.

\section{Episódio 01 - 08 e 09 de janeiro de 2014}

Esse episódio ocorreu no dia 09 de janeiro de 2014, caracterizando-se por apresentar um quadro sinótico que, já durante a manhã do dia anterior (08/01/2014) apresentava áreas de baixa pressão e complexos convectivos que se prolongavam pelo Nordeste Paraense e na tarde deste mesmo dia atingiu o litoral, dominando desde a Ilha de Marajó até a costa do Estado do Maranhão, no Nordeste Brasileiro.

Durante a noite do dia 08 por volta das 21h10min (00h10min do dia 09/01 GMT), conforme a figura 34, áreas de Instabilidade avançam da costa paraense em direção ao continente, atingindo a área urbana de Bragança com chuva forte, prolongando-se durante toda a madrugada até a manhã do dia 09/01/2014. Durante este evento, registrou-se uma média total de $132,0 \mathrm{~mm}$ de precipitação para os sete pluviômetros instalados na cidade, com registro máximo de $153,0 \mathrm{~mm}$ no posto 07 e mínimo de $105,0 \mathrm{~mm}$ no posto 06 , caracterizando-o como um evento de precipitação extrema (CONTI, 1998), cuja distribuição espacial na bacia hidrográfica do Igarapé Cereja e bairros adjacentes, pode ser melhor visualizada no mapa da Figura 5. 


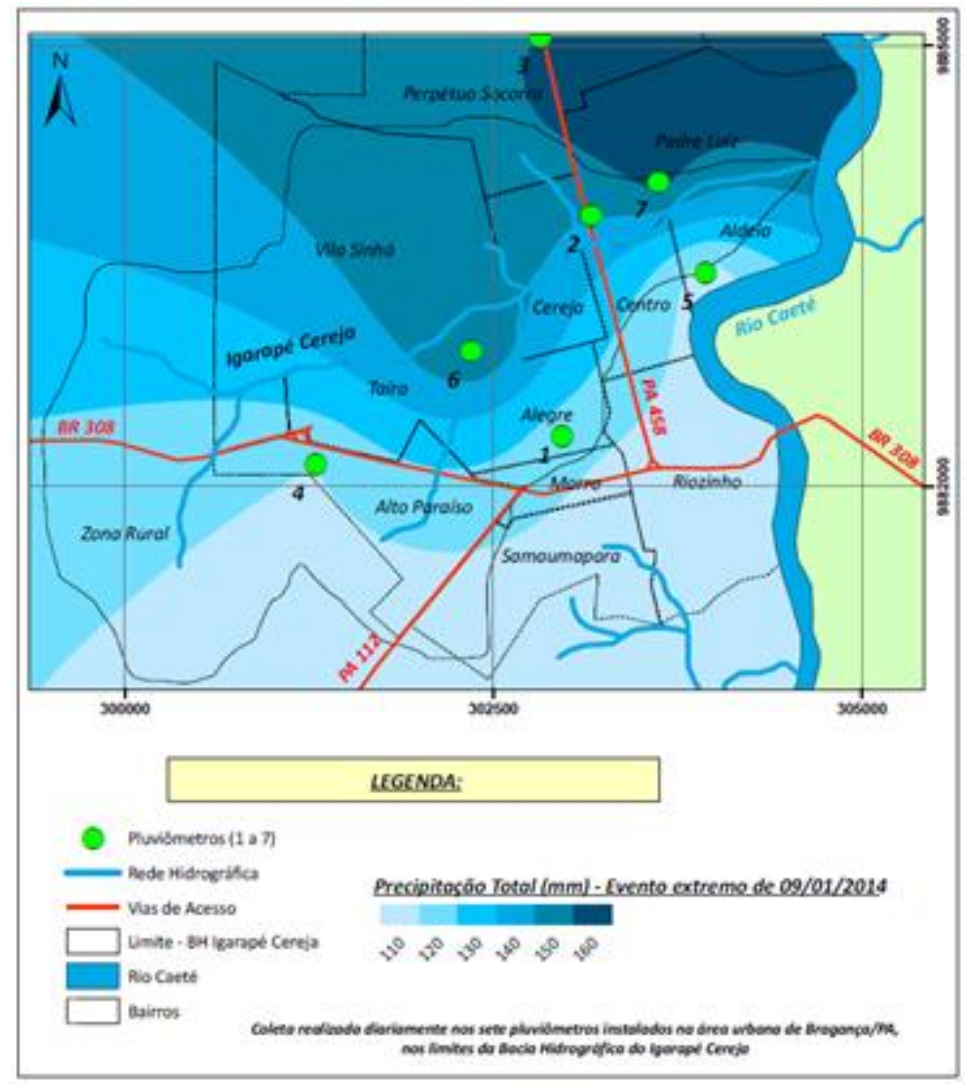

Figura 5: Precipitação Total (mm) - Evento extremo de 09/01/2014.

Analisando a variabilidade da precipitação na bacia hidrográfica do Igarapé Cereja durante esse evento, observa-se uma diferença de quase $50,0 \mathrm{~mm}$ de precipitação entre a área norte e sul. Na área norte, nos bairros Vila Sinhá, Perpétuo Socorro, Padre Luiz e Aldeia o volume de precipitação foi maior e onde houve registro de maiores danos na área urbana como pôde-se observar no mapa da Figura 5. Infelizmente, não há como comparar a quantidade de precipitação ocorrida em Bragança e na estação meteorológica de Tracuateua, uma vez que esta estava com problemas de registro de dados, o que acabou sendo solucionado nos dias seguintes.

O quadro sinótico que deflagrou este evento compõe-se da participação da Zona de Convergência Intertropical (ZCIT), dado que a ocorrência de chuva abundante, contínua, e durante a madrugada somente pode ser provocada por este sistema, uma vez que as Instabilidades Tropicais enfraquecem-se durante a noite pelo resfriamento da atmosfera.

Durante os dias anteriores ao evento, havia chovido pouco, um total de $17 \mathrm{~mm}$ para os oito dias iniciais do mês de janeiro, o solo ainda apresentava-se pouco seco devido a longa estiagem do Verão (Inverno e Primavera austral). Neste evento, o posto que registrou o maior total de chuva foi o de número 07, no bairro Padre Luiz. Foram registrados diversos pontos de alagamentos pela cidade, bem como elevação das águas do Igarapé Cereja, que invadiu algumas casas situadas às suas margens. Os bairros Aldeia, Padre Luiz, Perpétuo Socorro, Cereja, Centro, Abacateiro e Samaumapara foram os mais afetados pelos alagamentos e/ou transbordamento do rio.

No Centro da cidade a área comercial (que fica próximo ao bairro Padre Luiz) ficou alagada, durante a manhã os funcionários retiravam a água que invadiu os estabelecimentos, o mesmo se repetiu na Aldeia onde a água invadiu muitas casas e ruas situadas nas proximidades da foz do Igarapé Cereja e Rio Caeté. No bairro Padre Luiz, local de maior registro extremo de precipitação, moradores alugaram uma retroescavadeira que abriu um canal no meio da rua para escoar a água, que invadia as casas, até um córrego próximo (Figura 6). 


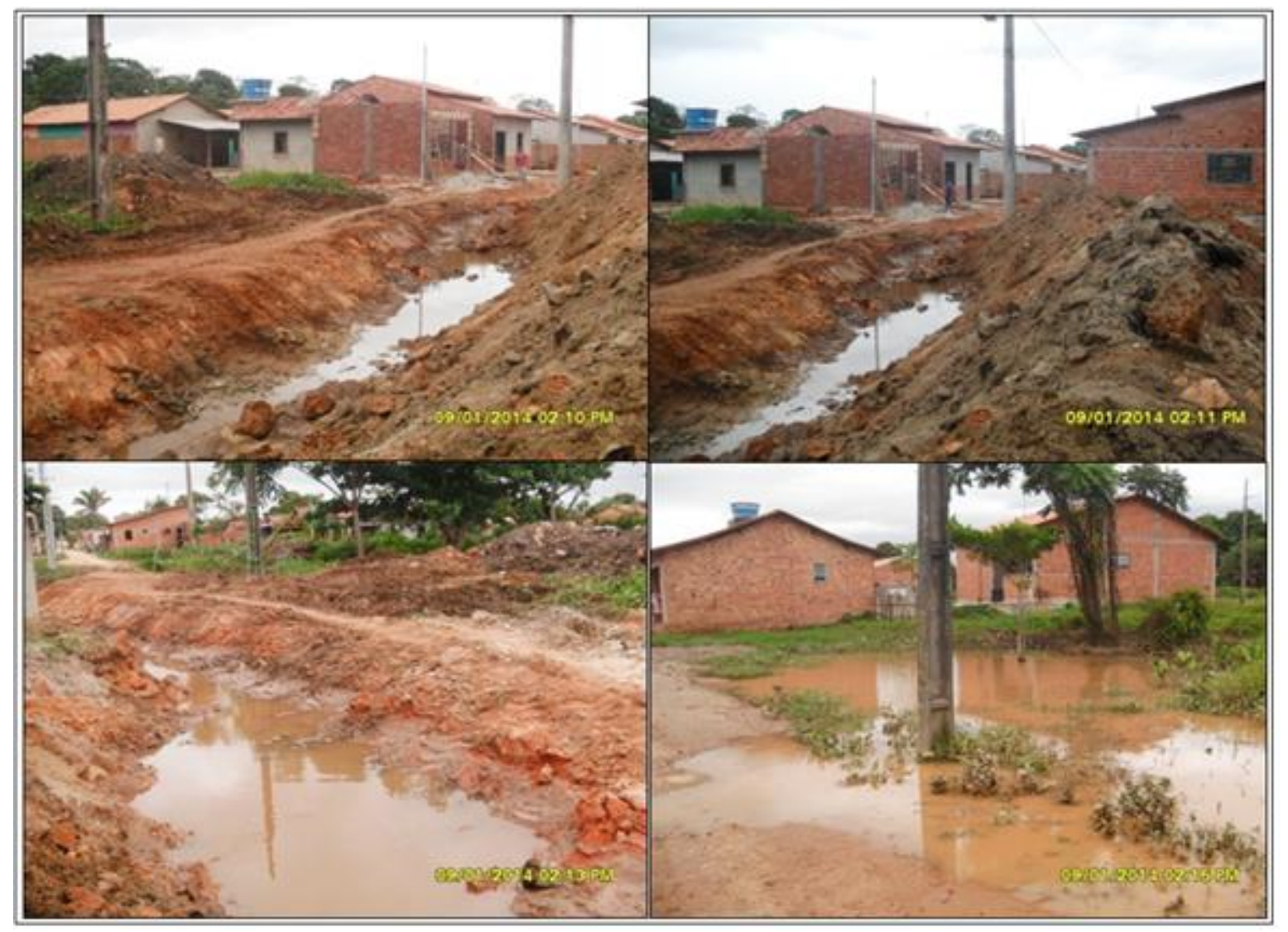

Figura 6: Abertura de canal com auxílio de retroescavadeira para escoamento das águas devido aos alagamentos na Travessa Santana, Bairro Padre Luiz.Fonte: registro de campo, COSTA, T.O; 2014.

\section{Episódio 02 - 05 e 06 de Fevereiro de 2014.}

Esse episódio caracterizou-se por apresentar durante a noite do dia 05 de fevereiro grande nebulosidade sobre a região, provocando algumas pancadas de chuva durante o inicio da noite, com volume de $25 \mathrm{~mm}$. Já no dia 06 por volta de $11 \mathrm{~h}$ 00min da manhã a atuação da CIT sobre o litoral do Pará trouxe instabilidade sobre a região provocando pancadas de chuva com volume de $40 \mathrm{~mm}$ (registrado no posto 01) durante pouco menos de 40 minutos.

Por volta de $11 \mathrm{~h} 55 \mathrm{~min}$ voltou a chover por uns $15 \mathrm{~min}$, aumentando a precipitação para um total de $67 \mathrm{~mm}$, quando foram identificados alagamentos nos bairros Aldeia, Padre Luiz, Perpétuo Socorro, Samaumapara e Cereja. O nível do Igarapé Cereja subiu, mas logo voltou às condições habituais com a perda da alimentação na vazão, evitando assim a ocorrência de enchente e danos significativos.

Durante este evento, o posto que registrou o maior total de chuva foi o de número 05 , no bairro Aldeia, com $107 \mathrm{~mm}$ nos dois dias, seguido do posto $02 \mathrm{com} 100 \mathrm{~mm}$ e 07 com total de $98 \mathrm{~mm}$. Fica evidente assim a maior concentração da precipitação sobre o médio e baixo curso do Igarapé seguindo a variabilidade da precipitação nesse evento que concentrou-se sobre o centro-norte e nordeste da bacia, enquanto o sul e sudoeste a precipitação foi menor (Figura 7).

\section{Episódio 03 - 16 de fevereiro de 2014}

Esse evento caracterizou-se pela atuação das ITs sobre a região durante toda a manhã e intensificação da CIT no inicio e final da tarde do domingo 16/02, provocando muita instabilidade atmosférica e deslocamento de nuvens carregadas do oceano em direção à costa paraense, acumulando uma média de 56,4 mm para os 07 postos instalados.

Nesse evento, a precipitação concentrou-se no norte e nordeste da bacia hidrográfica, com maior volume registrado no posto $03(70 \mathrm{~mm})$ ao norte da bacia, e menor no posto $04(42 \mathrm{~mm})$ no sentido sudoeste, totalizando uma diferença de $28 \mathrm{~mm}$ (Figura 8). 


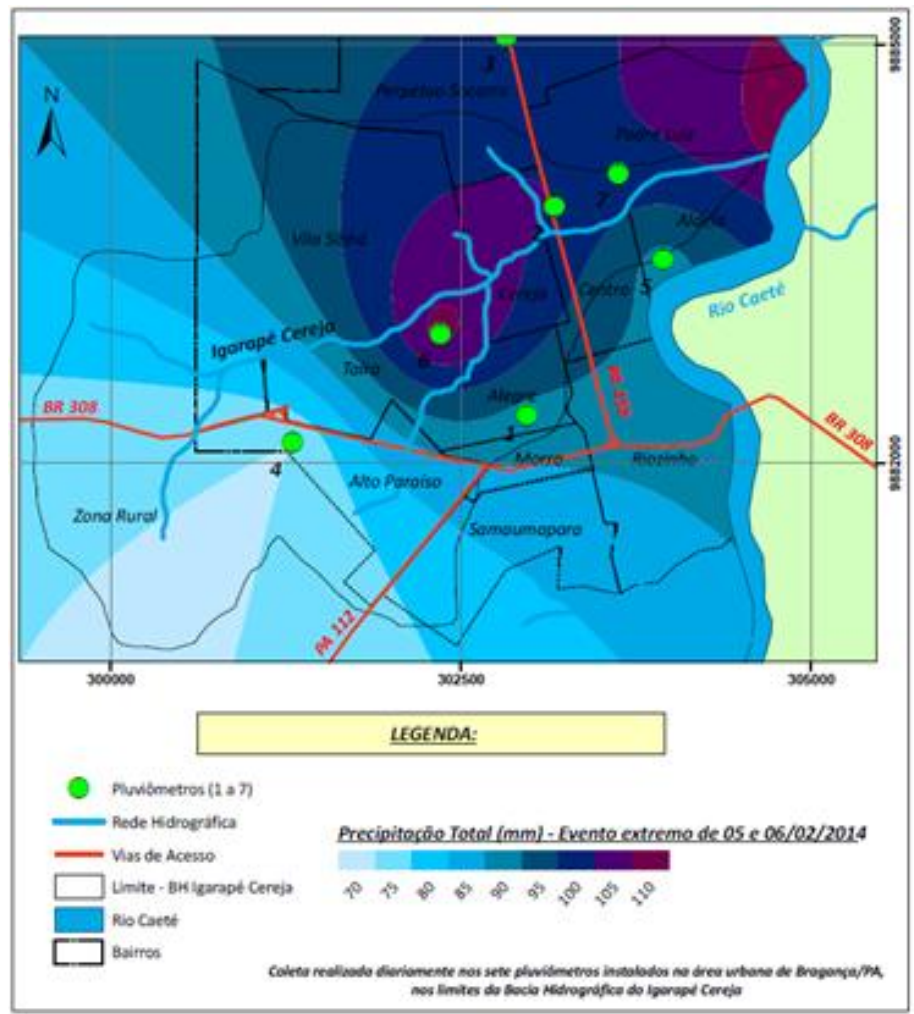

Figura 7: Precipitação Total (mm) - Evento extremo de 5-6 de fevereiro de 2014.

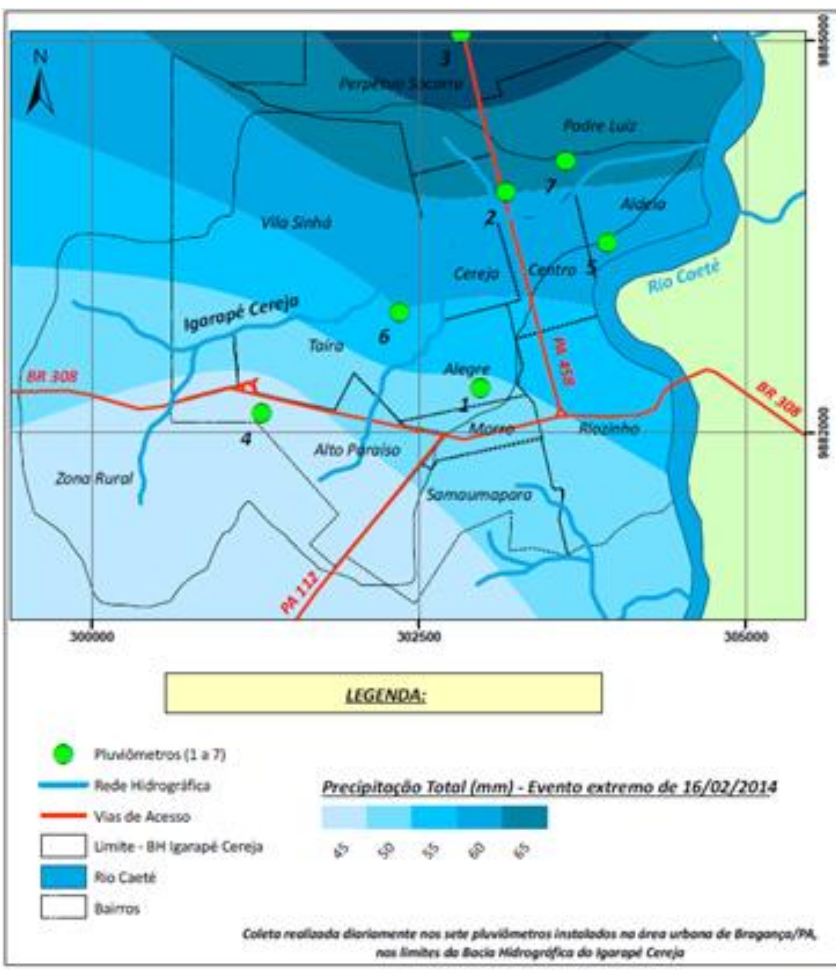

Figura 8 - Precipitação Total (mm) - Evento extremo de 16 de fevereiro de 2014. 


\section{Episódio 04 - 02 de março de 2014}

No dia 01 de março, a presença marcante da CIT sobre a região durante a noite possibilitou a formação de nuvens carregadas e grande volume de precipitação durante a madrugada e manha do dia 02/03, configurando o quadro sinótico que deflagrou o evento de precipitação extrema classificado como episódio 04.

Este episódio caracterizou-se por apresentar maior precipitação sobre o centro e nordeste da área da bacia hidrográfica, com totais de $85 \mathrm{~mm}$ no posto 05 (Nordeste), $80 \mathrm{~mm}$ no posto 03 (norte) e $75 \mathrm{~mm}$ no posto 06 (centro), e mínimo de $52 \mathrm{~mm}$ no posto 04 (sudoeste). A diferença entre o máximo e mínimo de precipitação neste episódio configurou-se entre os postos 05 e 04, com diferença de $33 \mathrm{~mm}$. Áreas no Centro, Aldeia e Perpétuo Socorro apresentaram alagamentos, e foi noticiado na televisão local que a água invadiu casas nas áreas adjacentes ao Igarapé Cereja, no bairro de mesmo nome, evidenciando um aumento no nível d'água e transbordamento do leito principal, configurando a enchente.

Observa-se que neste episódio que a variabilidade da precipitação segue o mesmo padrão diferencial de precipitação encontrado na precipitação mensal para os meses analisados, sempre com maior volume nos quadrantes norte e nordeste, e menor no sul e sudoeste da bacia hidrográfica. Neste caso, no entanto, observou-se um ligeiro deslocamento da precipitação na direção do centro da área da bacia hidrográfica, distribuindo a chuva sobre o médio e baixo curso do Igarapé (Figura 9).

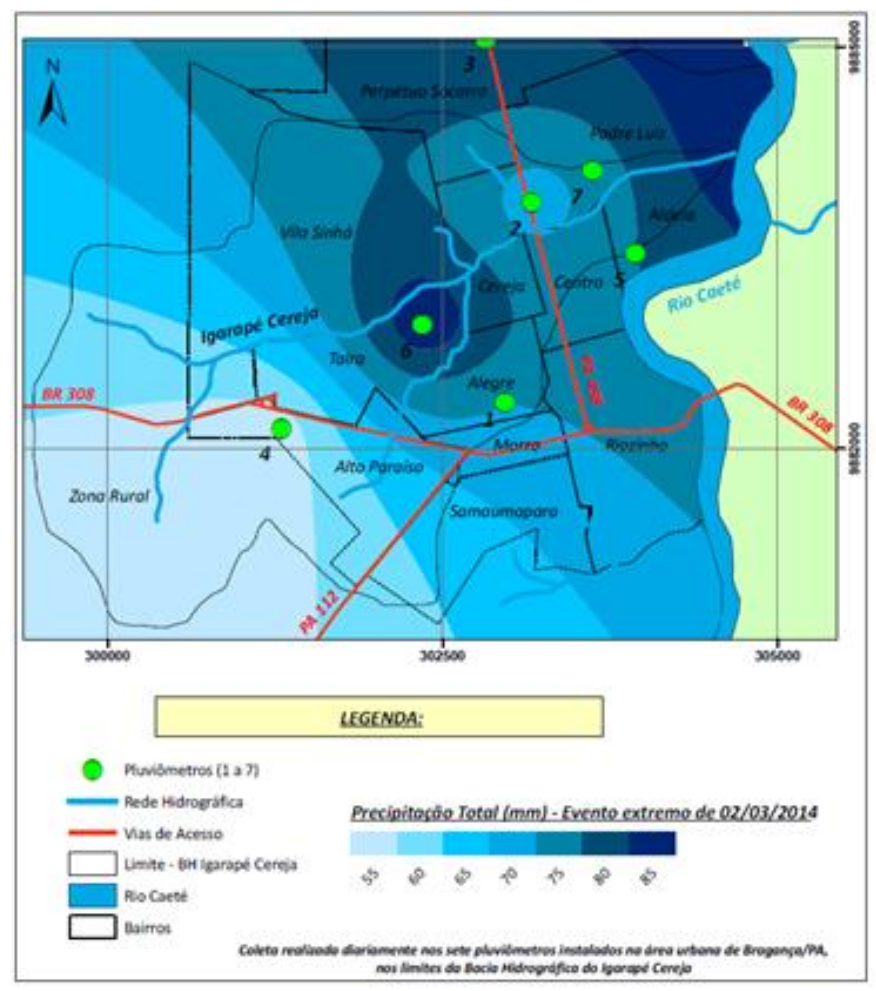

Figura 9: Precipitação Total (mm) - Evento extremo de 02 de março de 2014.

\section{Episódio 05 - 14 a 16 de março de 2014}

No dia 13 de março por volta das 22h30min $\left(01 \mathrm{~h} 30 \mathrm{~min}\right.$ de 14/03 GMT $\left.{ }^{2}\right)$, começou a chover e a trovejar forte durante horas, prolongando-se pela madruga ate inicio da manhã com volume de chuva de até $55 \mathrm{~mm}$ (posto 03) alagando o centro comercial. A chuva continuou até o dia 16/03 quando choveu forte no final da tarde e perdurou pela noite, alagando a área central e obrigando o comércio de domingo a fechar devido aos alagamentos e a falta de clientela que não dispôs a sair no temporal. A participação da CIT por longos períodos sobre a região favoreceu o grande volume de precipitação durante três dias consecutivos.

\footnotetext{
${ }^{2}$ Considerou-se no relato o inicio do evento no dia 13/03, por iniciar o evento às $22 \mathrm{~h} 30 \mathrm{~min}$ deste dia, porém consideraram-se os dados do dia 14/03 GMT (iniciado às 21h do dia 13/03, hora local) segundo normas da WMO. 
Durante esses dias (Figura 10) foi registrada maior variabilidade de precipitação entre o posto 05 $(131 \mathrm{~mm})$ e posto $04(92 \mathrm{~mm})$. Durante este evento observou-se a diferença de variabilidade entre o setor nordeste e sudoeste de $39 \mathrm{~mm}$ e problemas provocados pelas chuvas no dia 16/03 nos bairros Aldeia, Padre Luiz e Cereja e Taíra e Vila Nova (entre Taíra e Alegre, não disposto na divisão disponível na prefeitura local) devido elevação do nível do Igarapé Cereja, e, no Perpétuo Socorro e Vila Sinhá devido a alagamentos.

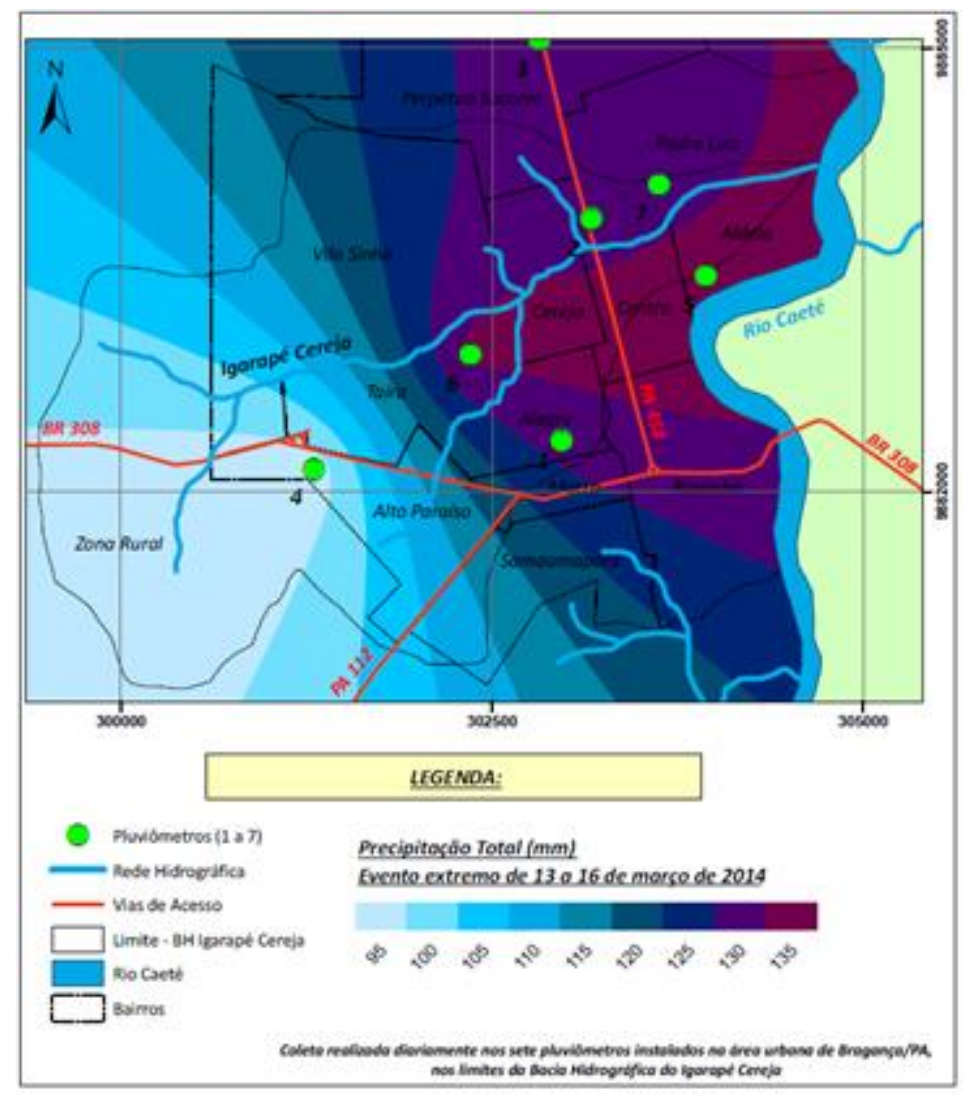

Figura 10: Precipitação Total (mm) - Evento extremo de 14-16 de março de 2014.

\section{Episódio 06 - 08 a 11 de abril de 2014}

O episódio 06 ocorreu entre os dias 08 e 11 de abril, acumulando nesse período um total de 220,7 mm de chuva. O pico de maior precipitação nesse episódio ocorreu durante o evento do dia 10/04 com 75,4 $\mathrm{mm}$ de precipitação acumulado em $24 \mathrm{~h}$. Esse episódio caracterizou-se pela presença do sistema atmosférico CIT sobre a região durante toda a primeira quinzena do mês, provocando chuva durante 06 dos 07 dias que antecederam o inicio dos eventos desse episódio, totalizando nesse intervalo um volume de $60,3 \mathrm{~mm}$, valor inferior ao precipitado somente no dia 10/04 (75,4mm).

Durante esse episódio observa-se nas imagens de satélite a presença constante de nebulosidade sobre a região com presença marcada durante toda a noite do dia 09 e prolongamento por todo o dia 10 , quando houve maior precipitação.

Durante esses eventos houve relatos de alagamentos nos bairros centro, Aldeia, Padre Luiz e Cereja. Segundo o noticiário televisivo local o nível do Igarapé Cereja se elevou invadindo algumas casas que se situam as proximidades do canal, porém sem provocar danos graves. Nesse episódio o posto 05 (nordeste) registrou maior precipitação com $255 \mathrm{~mm}$, seguido do posto 06 (centro) com $236 \mathrm{~mm}$. O posto 04 (sudoeste) seguiu o padrão que apresentou nos demais episódios, representando o mínimo com 196 mm, seguido do posto 01 (sul).

No mapa de variabilidade (Figura 11) deste episódio observa-se um centro de maior precipitação sobre o bairro Taíra, Vila Sinhá e Cereja, e outro registro anômalo sobre os bairros Aldeia e Padre Luiz. Nota-se que a pesar de uma maior concentração da precipitação sobre o bairro Taíra, este não apresentou danos ou problemas ocasionados pelas chuvas. Isso pode estar relacionado a presença maior nesse bairro de 
áreas com matas que retém o fluxo superficial das águas e equilibram a alimentação para o Igarapé, além de nessa área não haver grandes ocupações próximas ao canal principal.

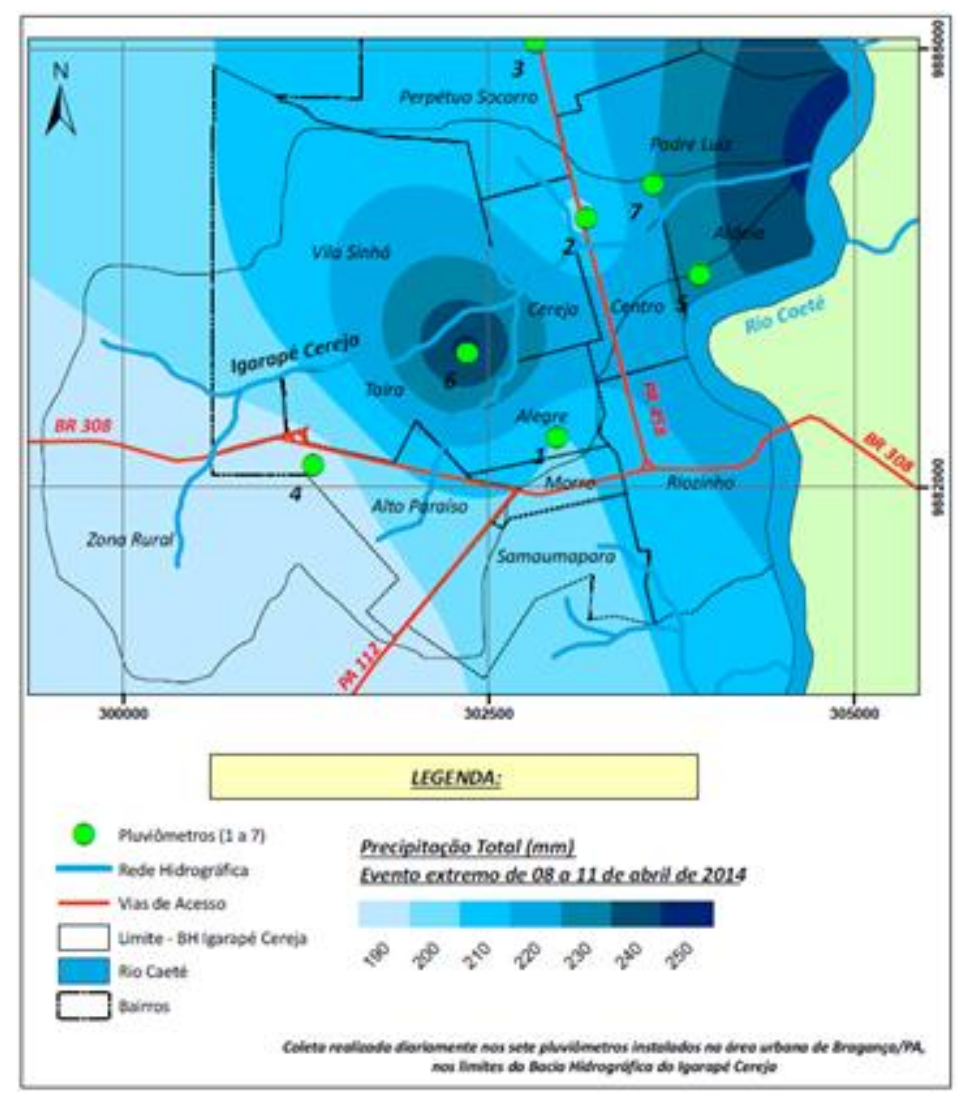

Figura 11: Precipitação Total (mm) - Evento extremo de 08-11 de abril de 2014.

\section{Episódio 07 - 27 e 28 de abril de 2014}

O episódio 07 apresentou precipitação total de $82 \mathrm{~mm}$, distribuídos $49,7 \mathrm{~mm}$ no dia 27/04 e 32,3 no dia 28/04. Essa configuração se deve ao fato do sistema atmosférico CIT ter penetrado na região durante o dia 26 , se intensificando durante a noite do dia 27 , provocando chuva forte com prolongamento pela madrugada do dia 28/04.

Durante esse episódio houve enchente no Igarapé Açaizal, tributário do Igarapé Cereja, no bairro Vila Nova (bairro não disposto na configuração disponível na prefeitura local, mas que se localiza nas confluências dos bairros Taíra, Alegre e Alto Paraíso, conforme informado por moradores do local. Também houve transbordamento do canal provocando enchente de pequena proporção na ocupação da COSANPA no bairro Cereja.

A variabilidade nesse episódio mostrou-se como a mais homogênea sobre a área da bacia hidrográfica, não apresentando valores diferenciais significativos entre os postos. Observa-se no mapa uma pequena variação na precipitação no setor leste, onde a quantidade foi menor (Figura 12).

\section{Episódio 08 - 01 e 02 de maio de 2014}

O episódio 08 é marcado pela presença da CIT sobre a região que desde março vem aumentando sua participação nas condições de tempo e atingindo seu pico de atuação nos meses de abril e maio. Nesse último, apresentando um decréscimo na participação desse sistema, se comparado ao mês anterior. Nesse evento houve relatos de alagamentos nos bairros Perpétuo Socorro e Padre Luiz, além da Vila Acarajó (área de expansão urbana localizada a $2 \mathrm{~km}$ ao norte da bacia, considerada como zona rural). Nesse evento foram registrados 78,9 mm de precipitação entre a tarde do dia 01/05 e a manhã dia 02/05. 
Considerando o mapa de variabilidade, o posto 05 registrou a menor precipitação $(55 \mathrm{~mm})$, seguido do posto $06(60 \mathrm{~mm})$. A concentração da precipitação localizou-se no setor norte, onde o posto 03 registrou $100 \mathrm{~mm}$, seguido do posto 07 , com $90 \mathrm{~mm}$. Observa-se que apesar do posto 05, que nos demais eventos estavam entre os que registraram maior precipitação, desta vez registrou a menor. Ainda assim, a variabilidade continuou evidenciando uma maior precipitação ao norte da bacia hidrográfica, desta vez no posto 03 (Figura 13).

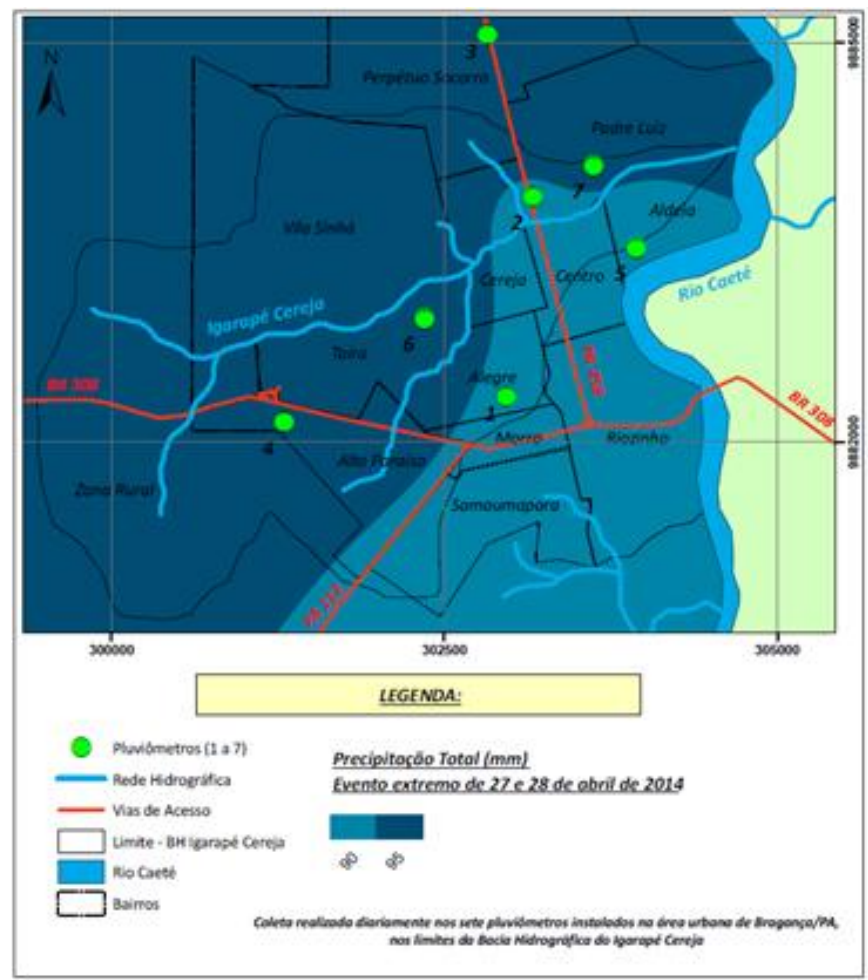

Figura 12: Precipitação Total (mm) - Evento extremo de 27-28 de abril de 2014.

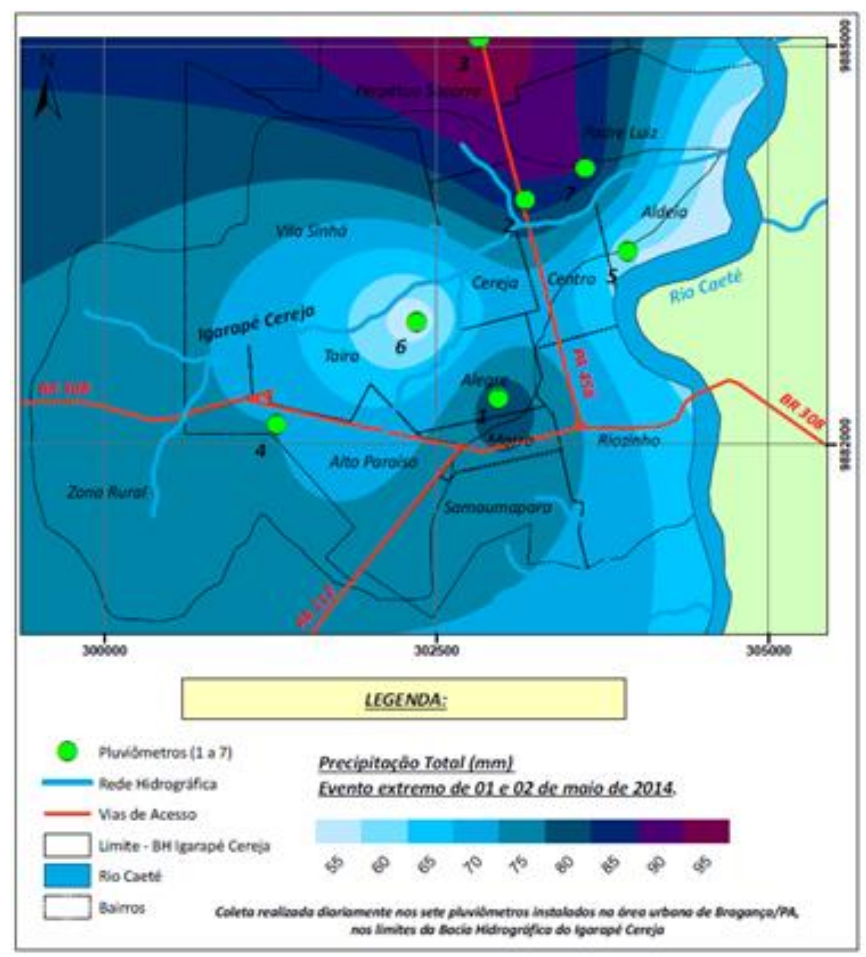

Figura 13: Precipitação Total (mm) - Evento extremo de 01-02 de maio de 2014. 


\section{Episódio 09 - 06 a 08 de maio de 2014}

A ação da CIT associada às ITs no dia 06 de maio e consequente predomínio de tempo chuvoso provocado pela Convergência Intertropical nos dias seguintes até o dia 08 do mesmo mês, proporcionou condições atmosféricas que desencadeou eventos extremos de precipitação nesse período, o qual classificouse como o episódio de número 09.

As condições atmosféricas no final da tarde e inicio da noite do dia 06 apresentam grande nebulosidade sobre o nordeste paraense com nuvens avançando do oceano sobre o continente na altura da cidade de Bragança, provocando grande precipitação com totais de 42,7 $\mathrm{mm}$ (média diária para os 7 postos).

A condição de instabilidade na noite do dia 06 continua sobre a madrugada do dia 07 avançando até o início da manhã desse dia quando a chuva cessou, voltando a ocorrer precipitação ao final da tarde e noite desse dia, registrando até esse momento mais $28,1 \mathrm{~mm}$ precipitados. Esse quadro prolongou-se pela madrugada do dia 08/05 quando se registrou mais $27,4 \mathrm{~mm}$ de precipitação, acumulando um total de 98,3 $\mathrm{mm}$.

Do total de precipitação acumulado nesse episódio, observou-se maior quantidade por posto o valor registrado no de número $06(128 \mathrm{~mm})$, seguido do posto $05(105 \mathrm{~mm})$. Seguindo a tendência contrária, os postos $02(83 \mathrm{~mm})$ e $07(89 \mathrm{~mm})$ registraram a menor quantidade. Com essas características, pôde-se elaborar o mapa mostrado da Figura 14. No mapa pode-se observar um maior volume precipitado sobre o nordeste e centro da bacia hidrográfica do Igarapé Cereja, enquanto o setor norte apresentou uma quantidade inferior, evidenciando um evento com variabilidade semelhante aos anteriores, mas com ligeira mudança se comparado o setor norte. Durante esse evento registrou-se enchente de baixa magnitude sobre os bairros Cereja, Padre Luiz e Aldeia, além de alagamentos no Centro e Perpétuo Socorro. Supõe-se que mesmo o volume precipitado tenha sido expressivo, os danos não foram maiores devido ao evento ter um maior prolongamento no espaço/tempo, o que favoreceu a vazão no Igarapé, registrando-se apenas elevações no nível das águas durante os picos.

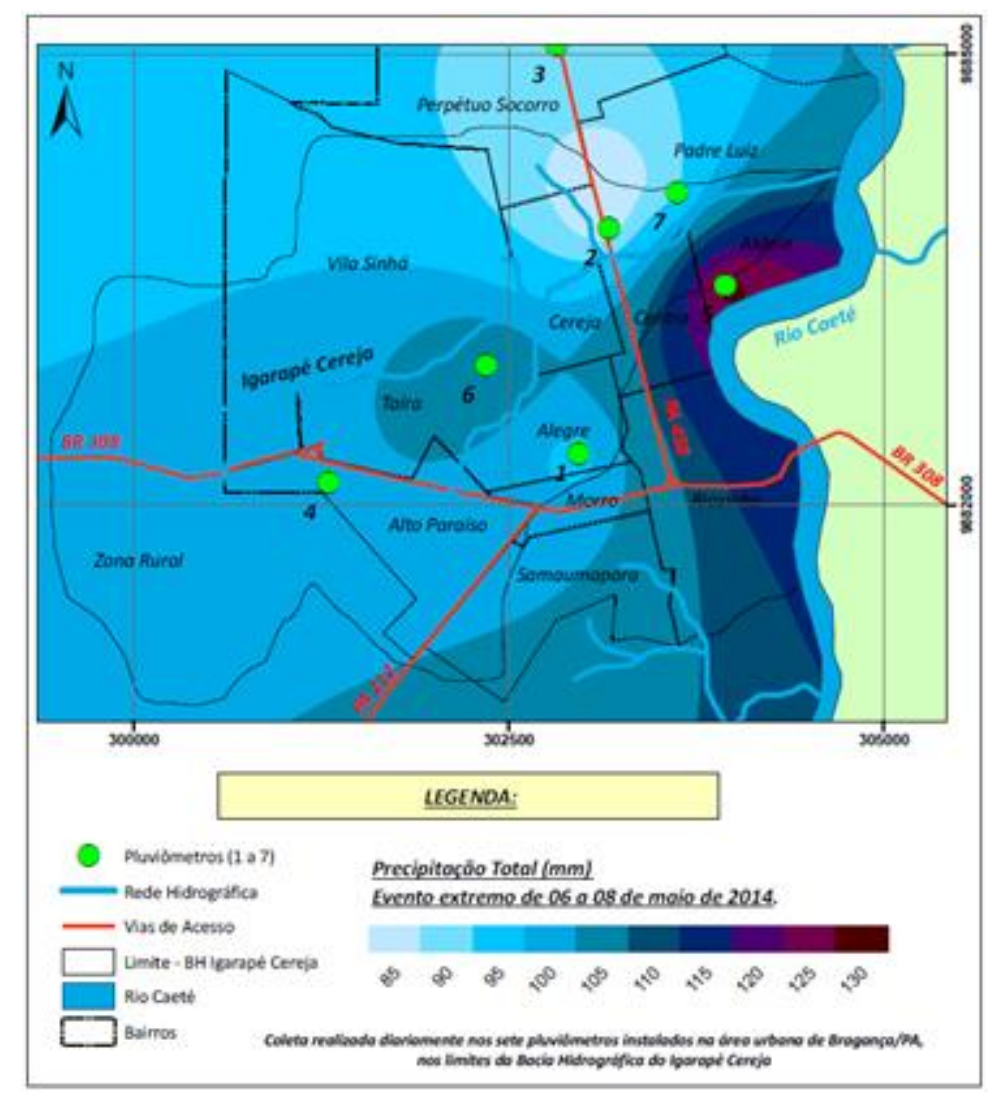

Figura 14: Precipitação Total (mm) - Evento extremo de 06-08 de maio de 2014. 


\section{Episódio 10 - 10 a 12 de maio de 2014}

No penúltimo episódio observado, de número 10, ocorrido entre os dias 10 e 12 de maio, as características atmosféricas foram semelhantes ao de número 09, tanto na presença dos sistemas atmosféricos, com presença da CIT associada a IT's no primeiro dia e permanência da CIT nos dois dias seguintes, quanto na quantidade de dias de duração do evento (3) e no volume precipitado 105,6 mm. Esse episódio diferencia-se, no entanto, na variabilidade da precipitação sobre a bacia hidrográfica, apresentando maior precipitação sobre o norte, centro e nordeste, e menor sobre o sul e sudoeste.

Nesse episódio os postos 03 (136 mm) e 07 (129 mm), nos bairros Perpétuo Socorro e Padre Luiz respectivamente, registraram maior precipitação enquanto a menor precipitação seguiu nos postos 04 (62 $\mathrm{mm})$ e 06 (83 mm), nos bairros Alto Paraíso e Taíra.

As condições de enchente do Igarapé Cereja voltaram a ocorrer no sentido do médio para o baixo curso, entre os bairros cereja e Aldeia, além do bairro Alegre, provocado por um canal tributário. A variabilidade da precipitação nesse episódio está mostrada na Figura 15.

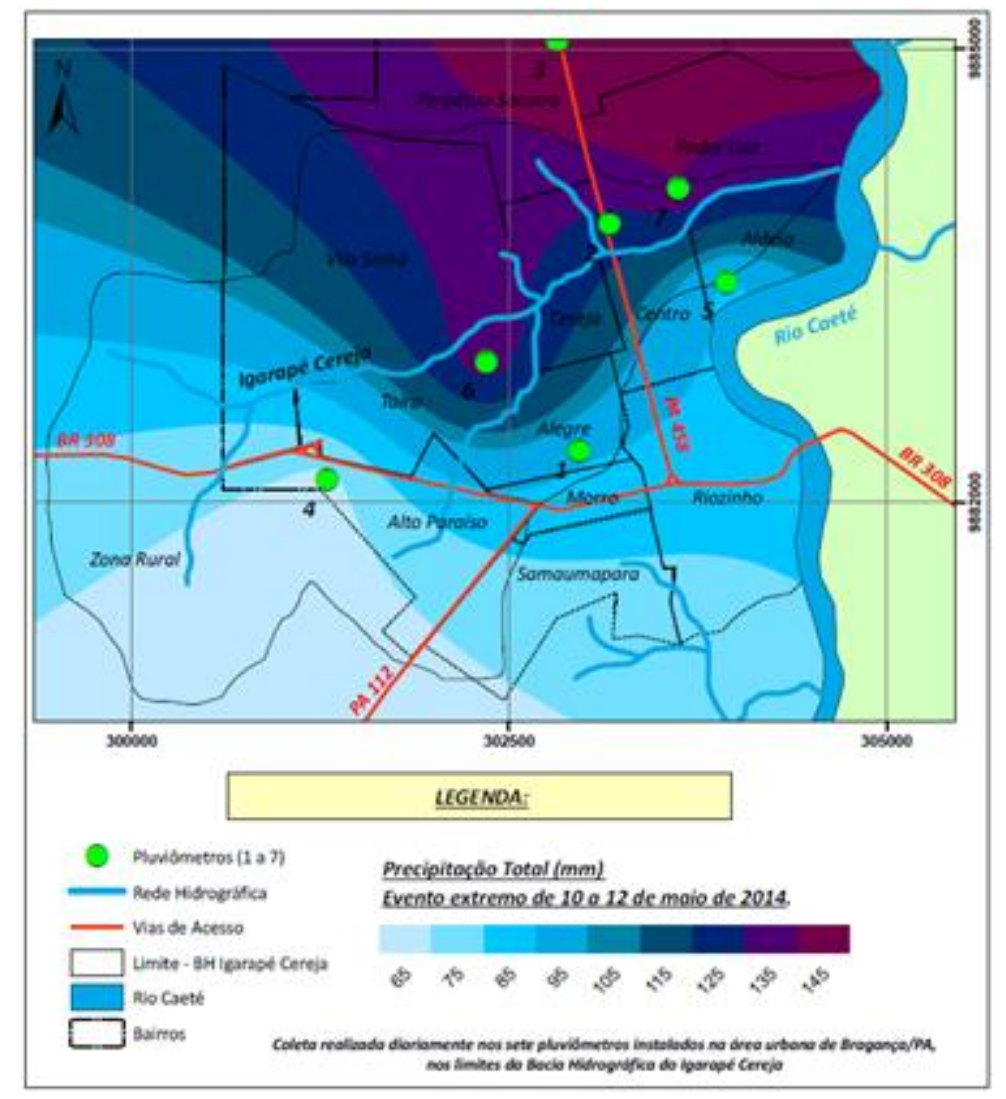

Figura 15 - Precipitação Total (mm) - Evento extremo de 10-12 de maio de 2014.

\section{Episódio 11: 20 a 22 de maio de 2014}

O último episódio analisado, o episódio 11, ocorreu nos dias 20, 21 e 22 de maio com participação de IT associada a CIT no dia 20, predomínio de IT no dia 21 e deste sistema associado a CIT no dia 22. Nesse episódio observou-se nebulosidade na tarde do dia 20, provocando chuvas durante a tarde e noite desse dia, acumulando um total de $18 \mathrm{~mm}$ até as 00h GMT (21h, hora local). Ainda durante a noite do dia 20 e madrugada do dia 21 a precipitação se intensifica, quando se observa a formação de uma grande linha de instabilidade sobre o litoral amazônico desde o Amapá, passando pelo Pará e atingindo o Maranhão, atuando até o inicio da manhã quando perde força e volta a intensificar-se no final da tarde, acumulando um total de $36,7 \mathrm{~mm}$ nesse dia.

Durante a tarde do dia 22 houve a presença de forte IT, que esteve associada à CIT provocando mais precipitação sobre a região, acumulando um total de $35,6 \mathrm{~mm}$. Para os três dias de evento foram registrados um total de 90,3 mm (Figura 16). 
Considerando a variabilidade, os setores norte e nordeste da bacia hidrográfica apresentaram maior precipitação, com $100 \mathrm{~mm}$ no posto $06,99 \mathrm{~mm}$ no posto $03 \mathrm{e} 94 \mathrm{~mm}$ no posto 05 . Os postos 07 (80 mm) e $04(83 \mathrm{~mm})$ apresentaram os menores valores.

Durante o pico deste evento foi registrado enchente de pouco impacto no Igarapé Cereja. O Nível da água do Igarapé transbordou o leito nos bairros Cereja, Padre Luiz e Aldeia, e alagamentos no Alegre e Centro.

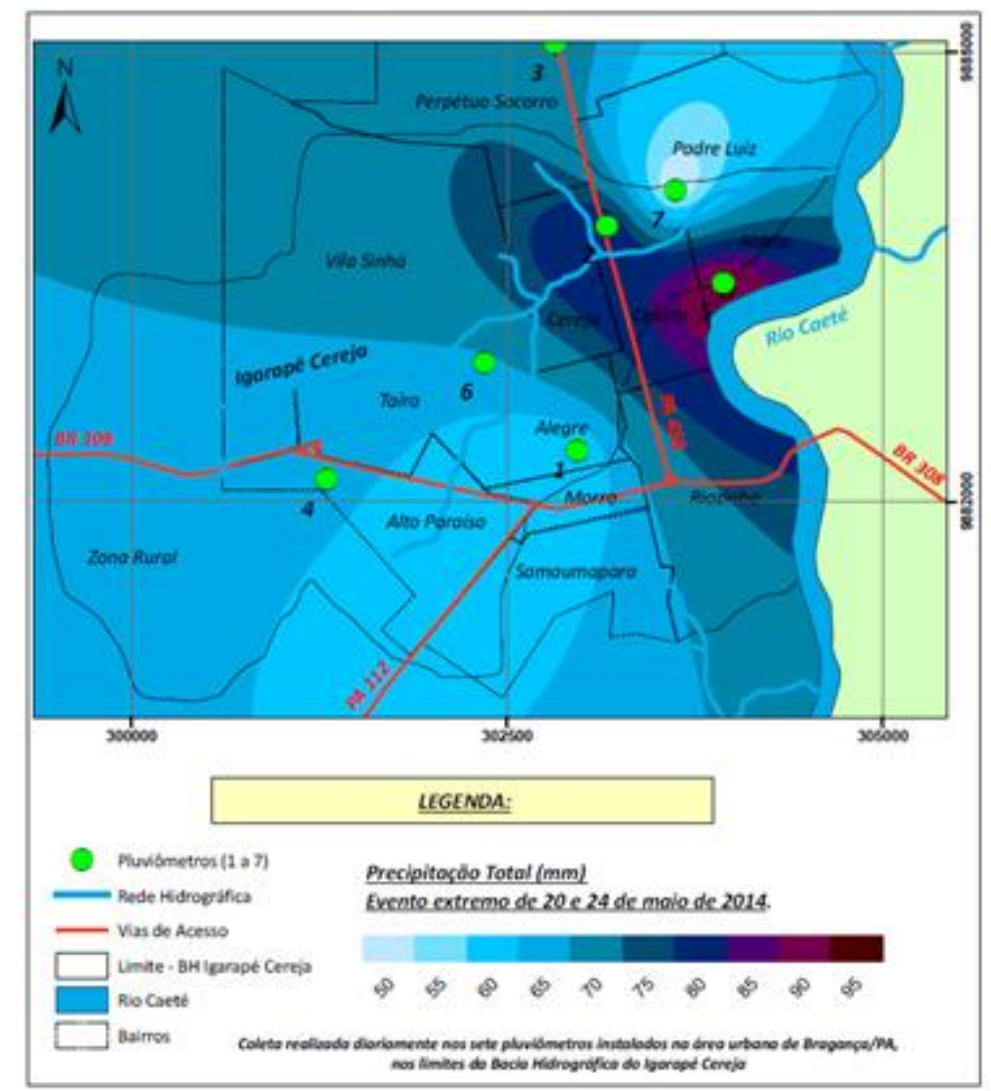

Figura 16: Precipitação Total (mm) - Evento extremo de 20-22 de maio de 2014.

\section{CONSIDERAÇÕES FINAIS}

Neste trabalho pretendeu-se estudar o clima urbano de Bragança/PA com ênfase ao terceiro canal de percepção Sistema Clima Urbano, o canal do impacto meteórico, uma vez que este é o canal que mais impactos negativos têm gerado ao meio urbano amazônico, sobretudo quando ocorrem as enchentes provocadas pelo transbordamento dos rios e igarapés, como o Cereja, em Bragança/PA. A partir do referencial teórico abordado, dos dados coletados em campo e sua posterior análise, considera-se alguns pressupostos observados e que impõem resultados à pesquisa.

Em 2014, registraram-se e analisaram-se 11 eventos de precipitação extrema ocorridos entre janeiro e maio, sendo que 07 deles foram provocados pela atuação da CIT e 04 pela atuação das ITs em associação com a CIT. Relacionando o histórico dos episódios de enchentes encontrou-se um mínimo de $62 \mathrm{~mm}$ de chuva acumulada em 24h capaz de gerar enchente no Igarapé Cereja e impacto no espaço urbano de Bragança, e um máximo já registrado de $212 \mathrm{~mm}$. Ao considerar os dados coletados em campo e a repercussão espacial observou-se, no entanto, que um mínimo de $56,4 \mathrm{~mm}$ em $24 \mathrm{~h}$ é capaz de gerar impactos.

As fortes chuvas ocorridas nesses eventos atingiram de forma mais intensa o setor norte e nordeste da bacia hidrográfica, área que compreende os bairros Vila Sinhá, Perpétuo Socorro, Padre Luiz, Cereja, Centro e Aldeia, provocando vários pontos de alagamentos e enchente do Igarapé Cereja em algumas áreas. De forma menos intensa, os eventos atingiram o setor centro da bacia, provocando enchente sobre o médio e baixo curso do Igarapé em ambos os casos. 
Os quadrantes sul e sudoeste da bacia hidrográfica do Igarapé Cereja apresentaram, de acordo com os dados coletados em campo, o menor volume precipitado na área da bacia, bem como os bairros situados nesses quadrantes os que apresentaram menos problemas ligados a pluviosidade. As áreas norte e nordeste da bacia apresentaram maior precipitação, enquanto o sul e sudoeste a menor, sendo a variação de até $161 \mathrm{~mm} /$ mês, registrado em abril de 2014 .

Por fim, observa-se que se considerados os extremos pluviométricos, pode-se ter como consequência um quadro de enchentes urbanas, que aliadas a características naturais da bacia de drenagem e também as alterações provocadas pela urbanização, tais como a impermeabilização do solo, retirada da vegetação natural e consequente aumento no escoamento superficial, provocam o aumento no fluxo de drenagem e intensificam os problemas.

Esse quadro é mais frequente em cidades tropicais devido às intervenções sobre o território não considerarem as características do clima local, sobretudo na região amazônica. Se considerações dessa natureza fossem relevadas em planejamentos urbanos, permitindo o escoamento da água com fluidez, maior permeabilidade do solo, manutenção de áreas verdes para aumento do tempo de manutenção da água na bacia, muitos dos episódios de chuvas extremas não resultariam em enchentes. Com isso, acredita-se que este trabalho pode ser utilizado no planejamento climático urbano do município e os dados coletados podem ser utilizados e ser motivadores de investigações futuras considerando a análise rítmica dos eventos extremos e as características do clima local e regional no Nordeste do Pará.

\section{REFERÊNCIAS}

AMORIM, M. C. C. T. O clima urbano de Presidente Prudente/SP. 2000. 374 f. Tese (Tese de Doutorado em Geografia) Universidade de São Paulo - USP, São Paulo. 2000.

AYOADE, J. O. Introdução à climatologia para os trópicos. Rio de Janeiro: Bertrand Brasil, 6. ed. 2003.

AZEVEDO, T. R. Os climas na cidade de São Paulo. São Paulo: USP/FFLCH/Laboratório de Climatologia, GEOUSP - Coleção Novos Caminhos-4, p.155-164. 2001.

AZEVEDO, T. R. Distribuição espacial da chuva: um ensaio metodológico. TARIFA, J. R. \& AZEVEDO, T. R. de, (Orgs). Os climas da cidade de São Paulo: teoria e prática, Coleção Novos Caminhos, n. 4, Departamento de Geografia, FFLCH, Universidade de São Paulo, São Paulo. 2001.

CONTI, J. B. Clima e meio ambiente. São Paulo, $3^{\text {a }}$ ed. Atual, 1998.

COSTA, P. P. R. Ocupação desordenada as margens do Rio Cereja, Bragança-Pará: realidades e desafios socioambientais. In: VII CONGRESSO NORTE NORDESTE DE PESQUISA E INOVAÇÃO CONNEPI, 2012, Palmas, Anais... Palmas: IFTO - Sistema eletrônico de administração de conferências, 2012.

EMPLASA/SNM. Disciplinamento do Uso e Ocupação do Solo com Vistas à Preservação de Inundações. In: EMPLASA / SNM. O Problema das Inundações na Grande São Paulo: Situação Atual e implementação de Diretrizes Metropolitanas de Drenagem. São Paulo: EMPLASA/SNM, p. 27-42. 1985.

FONZAR, B. C. A circulação atmosférica na América do Sul: os grandes sistemas planetários e subsistemas regionais que atingem o continente: localização e trajetórias. Rio de Janeiro, IBGE, Cadernos de Geociências, no 11, p. 11-33. 2005.

GARCIA, M. del C. M; VIDE, M. J. Algunas ideas propias de la climatología urbana de cara a la planificación urbana y rural. 2000. Conferência realizada no IV Simpósio Brasileiro de Climatologia Geográfica em 28 nov. 2000.

INSTITUTO BRASILEIRO DE GEOGRAFIA E ESTATÍSTICA, Dados Demográficos. IBGE, 2013. Disponível em <www.ibge.gov.br>. Acesso em 13 set 2013.

MONTEIRO, C. A. F. Teoria e Clima Urbano. São Paulo, EDUSP, (Série teses e monografias), n²5, 1976.

NIMER, E. Clima. In: Geografia do Brasil: Região sul. Rio de Janeiro, IBGE, v.05, 1977.

NIMER, E. Climatologia do Brasil. Rio de Janeiro, $2^{\text {a }}$ ed. IBGE, 1989.

SACHS, I. Ecodesenvolvimento: crescer sem destruir. São Paulo: Vértice, 1986. 
SARTORI, M. G. B. A dinâmica do clima no Rio Grande do Sul: indução empírica e conhecimento científico. Terra Livre. São Paulo, ano 19, v.1,n.20, p.27-49. Jan/jul. 2003.

SILVA, D. B. R. N. Os Donos de São Benedito: convenções e rebeldias na luta entre o catolicismo tradicional e devocional na cultura de Bragança, século XX. 2006. 202f. Dissertação de Mestrado (Mestrado em História Social da Amazônia) - Universidade Federal do Pará - UFPA, Belém-PA, 2006.

SILVEIRA, R. D. Relação entre tipos de tempo, eventos de precipitação extrema e inundações no espaço urbano de São Sepé - RS. 2007. 142f. Dissertação ( Mestrado em Geografia) Universidade Federal de Santa Maria - UFSM, Santa Maria - RS, 2007.

SPOSITO, M. E. B. Capitalismo e Urbanização. Contexto, 2000.

TUCCI, C. E. M. Gerenciamento da drenagem urbana. Revista Brasileira de Recursos Hídricos. Porto Alegre, v.7, n.1, jan/mar, 2002.

UVO. C. B. A Zona de Convergência Intertropical (ZCIT) e sua relação com a precipitação na Regiao Norte do Nordeste Brasileiro. 1989. 81f. Dissertação de Mestrado ( Mestrado em Meteorologia) Instituto Nacional de Pesquisas Espaciais - INPE, São José dos Campos - SP, 1989.

WOLLMANN, C. A; SIMIONI, J. P. D. Variabilidade espacial dos atributos climáticos na Estação Ecológica do Taim (RS), sob domínio polar. Revista do Departamento de Geografia - USP, Volume 25, p. 56-76. 2013.

WMO (1994). WORLD METEOROLOGICAL ORGANIZATION. Guide to Hydrological Practices, Data Acquisition and Processing, Analysis, forecasting and other applications. 5. Ed. N. 168. Genève. 1994. $259 \mathrm{p}$. 